Научный журнал КубГАУ, №124(10), 2016 года

УДК $630 * 266$

06.00.00 Сельскохозяйственные науки

СИСТЕМЫ ЗАЩИТНЫХ ЛЕСНЫХ

НАСАЖДЕНИЙ В УСЛОВИЯХ ЦЕНТРАЛЬНОГО ЧЕРНОЗЕМЬЯ РОССИИ

Михин Вячеслав Иванович

д.с.-Х.н., доцент

Михина Елена Александровна

к.с.-Х.н., доцент

Михин Дмитрий Вячеславович

Аспирант

Михина Виктория Вячеславовна

Студент

Воронежский государственный лесотехнический университет имени Г.Ф. Морозова, Воронеж,

Россия

В статье приведены показатели состояния защитного лесоразведения в ЦЧР, биометрические показатели роста, агроэкологическое влияние лесополос, продуктивность агротерриторий

Кючевые слова: ПОЛЕЗАЩИТНОЕ

ЛЕСОРАЗВЕДЕНИЕ, ПОКАЗАТЕЛИ

РОСТА, ЭКОЛОГИЯ ОБЛЕСЁННОГО

ПОЛЯ, ЭФФЕКТИВНОСТЬ ЛЕСОРАЗВЕДЕНИЯ
UDC $630 * 266$

Agriculture

\section{THE SYSTEM OF PROTECTIVE FOREST PLANTATIONS IN THE CONDITIONS OF CENTRAL CHERNOZEM REGION IN RUSSIA}

\author{
Mikhin Vyacheslav Ivanovich \\ Doctor of agricultural Sciences, associate Professor
}

Mikhina Elena Aleksandrovna

Candidate of agricultural Sciences, associate Professor

Mikhin Dmitry Vyacheslavovich, post-graduate student

Mikhina Victoria Vyacheslavovna student

Voronezh state forestry engineering University named after G. F. Morozov, Voronezh, Russia

The article presents the indicators of the protective afforestation of the Central black earth region, biometric growth index, agricultural and environmental impact of forest belts, efficiency of agroterritories

Keywords: FIELD-PROTECTIVE AFFORESTATION, GROWTH INDEX, ECOLOGY OF AFFORESTED FIELD, CROPS, EFFECTIVENESS OF AFFORESTATION

Doi: 10.21515/1990-4665-124-021

Под системой защитных насаждений понимается комплекс различного вида насаждений определённой структуры, взаимодействующих между собой и создающих мелиоративный эффект на определенной территории, который обеспечивает защиту сельскохозяйственных культур от неблагоприятных природных явлений $[1,7,8]$. Обустройство ландшафтов насаждениями и повышение ими лесистости является приоритетной задачей защитного лесоразведения [9, 10]. 
В условиях Центрального Черноземья в системе защитных насаждениях древесные породы в разных почвенных условиях имеют отличительные биометрические показатели роста (табл. 1).

В гнездовых посевах дуб черешчатый (Quércus róbur L.) в лесостепи при ширине лесополос 20 м к 35- летнему возрасту на чернозёме типичном (пробн. площ. 137) по высоте растет лучше на 12,8 \%, чем на черноземе выщелоченном (пробн. площ. 28). Наблюдаются также существенные различия в росте дуба (Дч) в этом же возрасте на чернозёме типичном и чернозёме выщелоченным и по диаметру ( на 17,0 \%). Насаждения произрастают по II и III классу бонитета. Следовательно, лучшие почвенные условия на чернозёме типичном способствуют повышению устойчивости и биометрических показателей роста дуба [2]. Используя модели роста дуба на разных почвах выявлено, что на чернозёме типичном до 11-12 лет, выщелоченном 16-18 лет отмечается замедленный рост по диаметру.

Берёза повислая (Bétula péndula Roth.) в степных условиях высокой энергией роста по диаметру и высоте обладает на чернозёме выщелоченном, по сравнению с другими почвенными условиями. Об этом свидетельствует анализ пробных площадей 182 и 308, заложенных в 3-х рядных полезащитных полосах в возрасте 17-18 лет. На чернозёме выщелоченном (пробн. площ. 182) средний диаметр берёзы (Бп) больше на 20,8 \%, высота на 26,6 \%, чем на чернозёме обыкновенном (пробн. площ. 308). 
Таблица 1 - Характеристика древесных пород в защитных насаждениях на разных почвах

\begin{tabular}{|c|c|c|c|c|c|c|c|c|}
\hline \multirow{2}{*}{$\begin{array}{l}\text { № } \\
\text { пр. } \\
\text { пл. }\end{array}$} & \multirow{2}{*}{$\begin{array}{c}\text { Поро- } \\
\text { да }\end{array}$} & \multirow{2}{*}{$\begin{array}{c}\text { Размеры } \\
\text { посадоч- } \\
\text { ных } \\
\text { мест }\end{array}$} & \multirow{2}{*}{$\begin{array}{c}\text { Число } \\
\text { рядов/ } \\
\text { Ширина, } \\
\text { м }\end{array}$} & \multirow{2}{*}{$\begin{array}{c}\text { Возраст, } \\
\text { лет }\end{array}$} & \multirow{2}{*}{$\begin{array}{c}\text { Сохран- } \\
\text { ность, } \\
\%\end{array}$} & \multicolumn{2}{|c|}{ Средние } & \multirow{2}{*}{$\begin{array}{c}\text { Бони- } \\
\text { тет }\end{array}$} \\
\hline & & & & & & $\begin{array}{c}\text { Диаметр, } \\
\text { см }\end{array}$ & Высота, м & \\
\hline 1 & 2 & 3 & 4 & 5 & 6 & 7 & 8 & 9 \\
\hline \multicolumn{9}{|c|}{ Лесостепь } \\
\hline \multicolumn{9}{|c|}{ Чернозём типичный } \\
\hline 137 & Дч & $5,0 \times 3,0$ & $4 / 20,0$ & 35 & 41,1 & $15,4 \pm 0,40$ & $12,3 \pm 0,20$ & II \\
\hline 267 & Бп & $2,5 \times 0,7$ & $3 / 7,5$ & 25 & 38,7 & $15,6 \pm 0,27$ & $14,0 \pm 0,31$ & Ia \\
\hline 64 & Тбз & $2,5 \times 1,0$ & $3 / 7,5$ & 17 & 79,3 & $16,5 \pm 0,31$ & $18,0 \pm 0,38$ & Ia \\
\hline 228 & Яо & $3,0 \times 0,7$ & $6 / 18,0$ & 36 & 67,5 & $18,3 \pm 0,42$ & $13,9 \pm 0,44$ & $\mathrm{I}$ \\
\hline \multicolumn{9}{|c|}{ Чернозём выщелоченный } \\
\hline 28 & Дч & $5,0 \times 3,0$ & $4 / 20,0$ & 36 & 41,2 & $12,3 \pm 0,19$ & $9,0 \pm 0,25$ & III \\
\hline 271 & БП & $2,5 \times 0,7$ & $3 / 7,5$ & 26 & 54,6 & $13,1 \pm 0,75$ & $12,5 \pm 0,61$ & Ia \\
\hline 75 & Тбз & $2,5 \times 1,0$ & $3 / 7,5$ & 17 & 66,1 & $11,9 \pm 0,55$ & $14,9 \pm 0,52$ & Ia \\
\hline 93 & Яо & $2,5 \times 0,7$ & $3 / 7,5$ & 37 & 32,0 & $18,2 \pm 0,59$ & $13,5 \pm 0,28$ & $\mathrm{I}$ \\
\hline \multicolumn{9}{|c|}{ Тёмно-серая лесная почва } \\
\hline 215 & Тбз & $1,5 \times 0,7$ & $7 / 10,5$ & 41 & 11,9 & $24,8 \pm 1,47$ & $21,4 \pm 1,10$ & Ia \\
\hline \multicolumn{9}{|c|}{ Серая лесная почвы } \\
\hline 65 & Яо & $1,5 \times 1,5$ & $9 / 13,5$ & 38 & 40,2 & $14,2 \pm 0,29$ & $10,6 \pm 0,35$ & III \\
\hline \multicolumn{9}{|c|}{ Степь } \\
\hline \multicolumn{9}{|c|}{ Чернозём типичный } \\
\hline 243 & Яо & $1,5 \times 0,7$ & $11 / 16,5$ & 36 & 34,8 & $16,4 \pm 0,91$ & $13,8 \pm 0,52$ & $\mathrm{I}$ \\
\hline \multicolumn{9}{|c|}{ Чернозём выщелоченный } \\
\hline 182 & БП & $2,5 \times 1,0$ & $3 / 7,5$ & 18 & 75,8 & $13,4 \pm 0,22$ & $13,5 \pm 0,36$ & Ia \\
\hline 52 & Тбз & $2,5 \times 1,0$ & $3 / 7,5$ & 17 & 71,3 & $13,5 \pm 0,40$ & $14,1 \pm 0,36$ & Ia \\
\hline 142 & Яз & $1,5 \times 0,7$ & $12 / 18,0$ & 19 & 54,4 & $15,8 \pm 0,43$ & $12,6 \pm 0,29$ & II \\
\hline \multicolumn{9}{|c|}{ Чернозём обыкновенный } \\
\hline 308 & БП & $2,5 \times 1,0$ & $3 / 7,5$ & 18 & 32,8 & $10,6 \pm 0,18$ & $9,9 \pm 0,22$ & Ia \\
\hline 307 & Тбз & $2,5 \times 1,0$ & $3 / 7,5$ & 19 & 46,3 & $15,3 \pm 0,32$ & $14,2 \pm 0,36$ & I \\
\hline 289 & Яз & $2,5 \times 0,7$ & $6 / 15,0$ & 39 & 46,4 & $12,9 \pm 0,32$ & $12,2 \pm 0,38$ & II \\
\hline 302 & Яо & $1,5 \times 0,8$ & $7 / 10,5$ & 40 & 46,3 & $15,3 \pm 0,31$ & $14,2 \pm 0,36$ & $\mathrm{I}$ \\
\hline
\end{tabular}

Отмечаются также различия биометрических показателей и в условиях лесостепи в 25 - 26 летних лесных полосах (пробн. площ. 267 и 271). При размещении посадочных мест $2,5 \times 0,7$ м берёза повислая на чернозёме типичном имеет больше диаметр на 19 \%, высоту - на 12,0 \%, чем на чернозёме выщелоченном. Некоторое снижение энергии роста по диаметру у 
берёзы повислой на чернозёмах отмечается с 16-20 лет, тёмно-серой лесной почве - 18 лет; выоте соответственно с 14 -18 и 17 лет. Следовательно, не менее плодородных почвах биометрические показатели роста берёзы повислой ниже, что важно учитывать при проектировании и создании искусственных линейных насаждений.

В лесных полосах в условиях лесостепи из тополя бальзамического (Populus balzamifera L.) заложены пробные площади № 64, 75, 307, 52 и 215. Сравниваемые насаждения (пробн. площ. 64 и 75) имеют ширину 4,5 м, размещение посадочных мест $-2,5 \times 1,0$ м, возраст 17 лет. Разница по диаметру и высоте тополя бальзамического (Тбз) в лесных полосах на чернозёме типичном по сравнению с выщелоченном составляет 4,6 см или $33,6 \%$ и 3,1 м или 20,8 \%; сохранность соответственна - 13,3\%. Выявлен также лучший рост тополя в условиях степи на чернозёме выщелоченным (пробн. площ. 52) в сравнении с чернозёмом обыкновенном (пробн. площ. 307) при прочих равных условиях (количество рядов, ширина, размещение). Так, средний диаметр тополя на пробной площади 52 выше на 32,3 \%, высота на $8,5 \%$, чем на пробной площади 307 , где разница в биометрических показателях существенна ( $\left.\mathrm{td}=6,87>\mathrm{t}_{0,05}=1,96 ; \mathrm{t}_{\mathrm{B}}=2,20>\mathrm{t}_{0,05}=2,01\right)$.

На тёмно-серой лесной почве в условиях лесостепи (пробн. площ. 215) тополь бальзамический при размещении 1,5 × 0,7 м имеет сохранность 11,9 \%, что свидетельствует о малой его устойчивости в защитном лесоразведении при достижении 41 года. Наблюдается снижение в росте тополя по диаметру на чернозёме типичном с 13-14 лет, выщелоченном - с 11-12, обыкновенном - с 10 и тёмно-серой лесной почве - с 11 лет; по высоте соответственно с 17 18, 15 - 16, 14 и 15 лет. Самые высокие биометрические показатели роста тополь бальзамический имеет на чернозём типичном, хорошие на выщелоченном и удовлетворительные чернозёме обыкновенном. 
Ясень обыкновенный (Fraxinus excelsior L.) на чернозёме типичном в условиях лесостепи (пробн. площ. 228) в лесной полосе шириной 18 м, при размещении 3,0×0,7 м к 36 годам достигает диаметра 18,3 см, высоты - 13,9 м и растет по I классу бонитета при сохранности $67,5 \%$.

В условиях степи на чернозёме типичном ясень обыкновенный (Яо) в возрасте 36 лет при размещении посадочных мест $1,5 \times 0,7$ м имеет сохранность 34,8 \%, средний диаметр - 16,4 см, среднюю высоту 13,8 м, произрастает по I классу бонитета (пробн. площ. 243). На чернозёме выщелоченном (пробн. площ. 93) в полезащитной полосе в возрасте 37 лет средний диметр составляет 18,2 см, высота - 13,5 м, бонитет - I. На чернозёме обыкновенном в степных условиях (пробн. площ. 302) чистое по составу насаждение из ясеня обыкновенного при сохранности 46,3 \% к 40 годам имеет средний диаметр 14,2 м, бонитет - I. На серой лесной почве в условиях лесостепи в полезащитной полосе шириной 13,5 м (пробн. площ. 65) ясень обыкновенный в возрасте 38 лет растёт лишь по III классу бонитета, его средняя высота составляет 10,6 м, средний диаметр - 14,2 см.

Ход роста ясеня обыкновенного в высоту совпадает с закономерностями роста по диаметру в зависимости от почвенных условий. При этом, возраст спада энергии по высоте и диаметру на чернозёме типичном и выщелоченным уже отмечается с 16-18 лет, а на чернозёме обыкновенном и серой лесной почве прослеживается замедленный рост до 13-14 лет.

На чернозёме выщелоченном и обыкновенном ясень зелёный (Fraxinus lanceolata L.) в степных условиях к возрасту 39 лет достигает диаметра 12,9 15,3 см, высоты - 12,6 - 12,9 м, бонитета - II и имеет сохранность 46,4 - 54,4 \% (пробн. площ. 142, 289). 
Самые низкие показатели роста ясень зелёный (Яз) имеет на чернозёме выщелоченном и обыкновенном. По данным моделей снижение энергии роста по высоте у ясеня зелёного на чернозёме типичном наблюдается с 18 лет, выщелоченном - с 16 лет, обыкновенном - с 14 лет; по диаметру соответственно с 10, 15, 12 лет.

Система защитных насаждений создаёт экологический эффект на межполосных полях. Особенно это проявляется в зимний период и период вегетации растений $[3,4,6]$.

Распределение снежного покрова в агролесоландшафтах среди лесополос в условиях ЦЧР приводится в таблице 2.

Таблица 2 - Снегоотложение и запас снеговой воды перед таянием на межполосных полях в системе защитных насаждений $(1990-2015$ гг.)

\begin{tabular}{|c|c|c|c|c|c|c|c|c|c|}
\hline \multirow{2}{*}{$\begin{array}{l}\text { Структу } \\
\text { ра } \\
\text { лесных } \\
\text { полос }\end{array}$} & \multicolumn{3}{|c|}{$\begin{array}{c}\text { Протяженность } \\
\text { снежного шлейфа, } \\
\text { м } \\
\text { Н (высот) }\end{array}$} & \multicolumn{2}{|c|}{$\begin{array}{c}\text { Наветренный } \\
\text { Шлейф }\end{array}$} & \multicolumn{2}{|c|}{$\begin{array}{c}\text { Заветренный } \\
\text { шлейф }\end{array}$} & \multicolumn{2}{|c|}{ Поле } \\
\hline & $\begin{array}{l}\text { навет- } \\
\text { рен- } \\
\text { ного }\end{array}$ & $\begin{array}{c}\text { завет- } \\
\text { рен- } \\
\text { ного }\end{array}$ & общая & $\begin{array}{c}\text { сред- } \\
\text { няя } \\
\text { высо- } \\
\text { та } \\
\text { снега, } \\
\text { см }\end{array}$ & $\begin{array}{c}\text { запас } \\
\text { воды, } \\
\text { мм } \\
\text { м }^{3} \\
\text { на } 1 \text { га }\end{array}$ & $\begin{array}{c}\text { сред- } \\
\text { няя } \\
\text { высо- } \\
\text { та } \\
\text { снега, } \\
\text { см }\end{array}$ & $\begin{array}{c}\text { запас } \\
\text { воды, } \\
\text { мм } \\
\text { м }^{3} \\
\text { на } 1 \text { га }\end{array}$ & $\begin{array}{c}\text { сред- } \\
\text { няя } \\
\text { высо- } \\
\text { та } \\
\text { снега, } \\
\text { см }\end{array}$ & $\begin{array}{c}\text { запас } \\
\text { воды, } \\
\text { мм } \\
\text { м }^{3} \\
\text { на } 1 \text { га }\end{array}$ \\
\hline$\Pi$ & $\begin{array}{r}70 \\
4,7 \\
\end{array}$ & $\begin{array}{c}180 \\
12,0\end{array}$ & $\begin{array}{l}250 \\
16,7\end{array}$ & $\begin{array}{c}15,5 \\
\pm 0,32\end{array}$ & $\begin{array}{r}41,8 \\
418 \\
\end{array}$ & $\begin{array}{c}16,4 \\
\pm 0,33\end{array}$ & $\begin{array}{r}45,5 \\
455 \\
\end{array}$ & $\begin{array}{c}11,9 \\
\pm 0,22\end{array}$ & $\begin{array}{l}35,9 \\
359 \\
\end{array}$ \\
\hline Аж & $\begin{array}{l}90 \\
6,0\end{array}$ & $\begin{array}{l}130 \\
8,7\end{array}$ & $\begin{array}{l}220 \\
14,7\end{array}$ & $\begin{array}{c}14,8 \\
\pm 0,40\end{array}$ & $\begin{array}{l}39,8 \\
398 \\
\end{array}$ & $\begin{array}{c}15,6 \\
\pm 0,29\end{array}$ & $\begin{array}{r}47,9 \\
479 \\
\end{array}$ & $\begin{array}{c}10,5 \\
\pm 0,17\end{array}$ & $\begin{array}{l}32,6 \\
326\end{array}$ \\
\hline $\mathrm{H}$ & $\begin{array}{l}30 \\
2,0\end{array}$ & $\begin{array}{l}60 \\
4,0\end{array}$ & $\begin{array}{l}90 \\
6,0\end{array}$ & $\begin{array}{c}13,8 \\
\pm 0,26\end{array}$ & $\begin{array}{l}35,6 \\
356\end{array}$ & $\begin{array}{c}14,4 \\
\pm 0,25\end{array}$ & $\begin{array}{r}41,9 \\
419\end{array}$ & $\begin{array}{c}9,4 \\
\pm 0,16\end{array}$ & $\begin{array}{l}30,2 \\
302\end{array}$ \\
\hline
\end{tabular}

Примечание: П-продуваемая, Аж- ажурная, Н- непродуваемая (плотная) структура лесных полос. 
Протяжённость снежного шлейфа за лесными полосами продуваемой структуры составила 180 м или $12,0 \mathrm{H}$, а ажурной - 130 м или $8,7 \mathrm{H}$, непродуваемой - 60 м или 4,0Н. С наветренной стороны самый короткий шлейф (30 м) отмечается у плотных насаждений. Максимальная высота снежного покрова образуется на расстоянии 20 м от продуваемых лесополос, 15 м - ажурных, на заветренной опушке - плотных по структуре.

Наибольший запас снеговой воды в наветренных шлейфах отмечается от полезащитных полос продуваемой структуры (41,8 мм или 418 м $^{3}$ на 1 га), что на 7,9 \% выше, чем у ажурных и на 20,1 \%, чем от плотных насаждениях. С заветренной стороны минимальные запасы снеговой воды (35,6 мм или 356 $\mathrm{m}^{3}$ на 1 га) находится в шлейфе плотных лесных полос. Вне зоны влияния полезащитных насаждений средняя высота снежного покрова составила 9,4 11,9 см и запас снеговой воды 302 - 359 м $^{3}$ на 1 га. Коэффициент варьирования мощности снежного покрова по изучаемым снегомерным маршрутам составил 9,1 - 15,7 \%. Различия по высоте снега и его запасам в приполосных и межшлейфовых зонах составляют 22,0 - 28,1\%.

Длительное произрастание защитных насаждений в агролесоландшафте приводит к изменению почвенных условий $[4,5]$. Так, в системе лесополос на различном удалении от насаждений имеются определённые различия в физико-химических показателях почв (табл. 3). Данные разрезов, заложенных в 30 м от лесных полос и в центре пашни свидетельствуют о повышенном содержание перегноя в гор Ап в почвах, расположенных ближе к насаждениям. Рядом с лесной полосой создаются наиболее благоприятные гидротермические условия в течение всего вегетационного периода, что увеличивает биомассу органического вещества, поступающего в почву и активизирующего деятельность микроорганизмов и почвенных беспозвоночных. Более интенсивная минерализация и гумификация органических 
остатков приводит к образованию и лучшему накоплению гумуса в верхнем слое почвы. В процессе более интенсивной минерализации усиливается биогенная аккумуляция кальция и магния. Одна часть этих катионов увеличивает сумму обменных оснований и ёмкость обмена, другая нейтрализует почвенный раствор. В результате наблюдается тенденция к повышению степени насыщенности почв основаниями на участках пашни, прилегающих к лесной полосе.

Таблица 3 - Влияние защитных насаждений на физико-химические свойства чернозёмов выщелоченных

\begin{tabular}{|c|c|c|c|c|c|c|c|c|c|c|c|}
\hline \multirow{2}{*}{$\begin{array}{l}\text { Гори } \\
\text { зонт }\end{array}$} & \multirow{2}{*}{$\begin{array}{l}\text { Глу } \\
\text { би } \\
\text { на, } \\
\text { см }\end{array}$} & \multirow{2}{*}{$\begin{array}{l}\text { Гумус, } \\
\%\end{array}$} & \multirow{2}{*}{$\begin{array}{l}\mathrm{pH} \\
\text { соле } \\
\text { вой }\end{array}$} & \multicolumn{4}{|c|}{ мг-экв. на 100 г почвы } & \multirow{2}{*}{$\begin{array}{l}\text { Ём } \\
\text { кость } \\
\text { обме } \\
\text { на }\end{array}$} & \multirow{2}{*}{\begin{tabular}{|l} 
Сте \\
пень \\
насы \\
щен \\
ности
\end{tabular}} & \multicolumn{2}{|c|}{ МГ/Кг } \\
\hline & & & & $\mathrm{Ca}^{2+}$ & $\mathrm{M}^{2+}$ & $\begin{array}{l}\text { Сум } \\
\text { MA }\end{array}$ & $\begin{array}{l}\mathrm{H}^{+} \\
\text {гид } \\
\text { ро } \\
\text { лит } \\
\end{array}$ & & & $\mathrm{P}_{2} \mathrm{H}_{5}$ & $\mathrm{~K}_{2} \mathrm{O}$ \\
\hline \multicolumn{12}{|c|}{ Разрез 78, лесная полоса 33 лет } \\
\hline $\mathrm{A}$ & $1-11$ & 5,89 & 5,32 & 23,0 & 4,14 & 27,7 & 3,1 & 3,08 & 89,9 & 48,7 & 43,4 \\
\hline $\mathrm{AB}$ & $40-50$ & 5,27 & 5,37 & 24,0 & 3,59 & 27,6 & 2,4 & 29,9 & 92,3 & 127,0 & 120,1 \\
\hline $\mathrm{B}_{1}$ & $70-80$ & 3,74 & 7,11 & 24,0 & 3,10 & 27,1 & 2,0 & 29,1 & 93,1 & - & - \\
\hline $\mathrm{B}_{2}$ & $100-110$ & 2,69 & 7,21 & \multicolumn{8}{|c|}{ вскипает } \\
\hline $\mathrm{C}$ & $140-150$ & 0,54 & 7,27 & \multicolumn{8}{|c|}{ вскипает } \\
\hline \multicolumn{12}{|c|}{ Разрез 78(1), пашня, 30 м (5Н3) от лесной полосы } \\
\hline Ап & $0-20$ & 5,80 & 6,06 & 23,4 & 3,93 & 27,3 & 2,9 & 30,2 & 90,4 & 49,5 & 39,6 \\
\hline $\mathrm{AB}$ & $40-50$ & 4,61 & 6,09 & 23,4 & 3,34 & 26,8 & 2,3 & 29,1 & 92,1 & 63,2 & 41,6 \\
\hline $\mathrm{B}_{1}$ & $60-70$ & 3,19 & 6,54 & 24,2 & 2,96 & 27,2 & 1,8 & 28,9 & 94,1 & 63,7 & 45,6 \\
\hline $\mathrm{B}_{2}$ & $100-110$ & 2,31 & 7,13 & 21,2 & 3,17 & 24,4 & \multicolumn{5}{|c|}{ вскипает } \\
\hline $\mathrm{C}$ & $140-150$ & 0,75 & 7,19 & 21,7 & 3,19 & 24,9 & \multicolumn{5}{|c|}{ вскипает } \\
\hline \multicolumn{12}{|c|}{ Разрез 78(2), пашня, 150 м (10Нз) от лесной полосы } \\
\hline Ап & $0-20$ & 5,37 & 6,06 & 23,2 & 3,86 & 27,1 & 3,0 & 30,1 & 90,0 & 35,8 & 39,1 \\
\hline $\mathrm{AB}$ & $40-50$ & 5,37 & 5,83 & 23,0 & 2,66 & 25,7 & 2,3 & 28,0 & 91,8 & 47,3 & 35,5 \\
\hline $\mathrm{B}_{1}$ & $80-90$ & 3,34 & 5,88 & 23,7 & 2,54 & 26,3 & 2,0 & 28,2 & 93,3 & 59,3 & 36,8 \\
\hline $\mathrm{B}_{2}$ & $100-110$ & 2,32 & 5,98 & 23,6 & 2,43 & 26,0 & 1,2 & 27,2 & 95,6 & 12,2 & 38,5 \\
\hline $\mathrm{C}$ & $140-150$ & 0,98 & 7,11 & 21,5 & 3,76 & 25,3 & & & вскипае & & \\
\hline
\end{tabular}


Нейтрализуя кислые продукты разложения органических остатков, биогенный кальций создаёт здесь благоприятную нейтральную среду (pH 6,06 $6,54)$.

Активная реакция почвы пашни, удаленной от лесной полосы на 150 м близка к нейтральной ( $\mathrm{pH} 5,8$ - 6,06). В самой же полосе за 33 года её существования произошло снижение рН в верхнем 50-ти см слое почвы до 5,3 - 5,4, в связи с сокращением поступления кальция.

В результате положительного мелиоративного воздействия защитных насаждений на ландшафт изменяется биопродуктивность искусственных фитоценозов. Согласно наших расчётов в целом по ЦентральноЧернозёмному региону только от влияния полезащитных (ветроломных) лесных полос дополнительная ежегодная продукция растениеводства (по озимой пшенице) составляет 11700 тыс.ц, что оценивается в энергетическом эквиваленте - 10858 ГДж и денежном выражении (прибыль) - 6244289 тыс. руб.

На основании вышеизложенного представляется возможным сделать следующие выводы:

1. Лучший рост и сохранность в возрасте 17- 41 года дуб черешчатый, берёза повислая, тополь бальзамический, ясень обыкновенный и зелёный в лесных полосах имеют на чернозёме типичном (на 8,5 - 32,3\%) по сравнению с другими почвенными условиями. На черноземах, тёмно-серой и серой лесной почве у них отмечается снижение в энергии роста по высоте и диаметру уже с возраста 11 - 20 лет, что важно учитывать при формировании лесомелиоративных систем.

2. В системе лесных полос ветроломного назначения наибольший по протяжённости снежный шлейф (до $12 \mathrm{H}$ ) формируется среди насаждений продуваемой структуры, который длиннее в 1,38 раза от ажурных и 3,00 раза 
плотных насаждений. Запас снеговой воды в приполосных зонах искусственных линейных насаждений выше на 21,6 - 34,5\%, чем на незащищённых участках агроландшафтов.

3. В результате длительного воздействия защитные насаждения до $5 \mathrm{H}$ (высот) в мелиоративной зоне улучшают степень насыщенности почв основаниями, показатель гумусированности. Биогенный кальций создаёт благоприятную нейтральную среду.

4. В защищённых лесоаграрных ландшафтах ЦЧР, занятых озимой пшеницей урожай выше на 11700 тыс. ц по сравнению с малооблесёнными участками угодий. Ежегодная прибыль от получаемой дополнительной продукции растениеводства составляет 6 мрд. руб.

\section{Список литературы}

1.Захаров, В. В. Агролесомелиоративное земледелие. / В.В. Захаров, В.М. Кретинин - Волгоград : ВНИАЛМИ, 2005. - 217 с.

2.Искусственные линейные насаждения в условиях Среднерусской возвышенности [Текст] / М.П. Чернышов, В.И. Михин, Е.А. Михина, Д.В. Михин, В.В. Михина // Лесотехнический журнал - 2016. - Т. 5, № 4 (20). - С. 43-50

3.Методика системных исследований лесоаграрных ландшафтов. - М. : ВАСХНИЛ, 1985. $-112 \mathrm{c}$.

4. Михин, В. И. Лесомелиорация ландшафтов. / В.И. Михин. - Воронеж, 2006. - 127 с.

5.Михин, В.И. Роль полезащитных насаждений в преобразовании ландшафтов Центрального Черноземья / В.И. Михин, Е.А. Михина, Д.В. Михин // Лесотехнический журнал. -2015. Т.5, № 4 (20). - С. 43 - 50.

6. Павловский, Е. С. Экологические и социальные проблемы агролесомелиорации. / Е.С. Павловский. - М. : Агропромиздат, 1988. - 181с.

7. Родин, А. Р. Лесомелиорация ландшафтов. / А.Р. Родин, С.А. Родин. -М . : МГУЛ, 2007. -165 c.

8. Стратегия развития защитного лесоразведения в Российской Федерации на период до 2020 года / К. Н. Кулик [и др.]. - Волгоград : ВНИАЛМИ, 2008. - 34 с.

9. Effects of Governance on Availability of Land for Agriculture and Conservation in Brazil / G. Sparovek [ et al.] // Environmental Science and Technology. - 2015. - Vol. 49, Issue 17. - P. 10285-10293.

10. Forest restoration following surface mining disturbance: challenges and solitions / S. E. Macdodals [ et al.] // New Forests. - 2015. - V. 46., Issis 5 - 6 . P. 703 - 732. 


\section{References}

1.Zaharov, V. V. Agrolesomeliorativnoe zemledelie. / V.V. Zaharov, V.M. Kretinin Volgograd : VNIALMI, 2005. - 217 s.

2.Iskusstvennye linejnye nasazhdenija v uslovijah Srednerusskoj vozvyshennosti [Tekst] / M.P. Chernyshov, V.I. Mihin, E.A. Mihina, D.V. Mihin, V.V. Mihina // Lesotehnicheskij zhurnal - 2016. - T. 5, № 4 (20). - S. 43-50

3.Metodika sistemnyh issledovanij lesoagrarnyh landshaftov. - M. : VASHNIL, 1985. $112 \mathrm{~s}$.

4. Mihin, V. I. Lesomelioracija landshaftov. / V.I. Mihin. - Voronezh, 2006. - 127 s.

5.Mihin, V.I. Rol' polezashhitnyh nasazhdenij v preobrazovanii landshaftov Central'nogo Chernozem'ja / V.I. Mihin, E.A. Mihina, D.V. Mihin // Lesotehnicheskij zhurnal. -2015. T.5, № 4 (20). - S. $43-50$.

6. Pavlovskij, E. S. Jekologicheskie i social'nye problemy agrolesomelioracii. / E.S. Pavlovskij. - M. : Agropromizdat, 1988. - 181s.

7. Rodin, A. R. Lesomelioracija landshaftov. / A.R. Rodin, S.A. Rodin. -M . : MGUL, 2007. $165 \mathrm{~s}$.

8. Strategija razvitija zashhitnogo lesorazvedenija v Rossijskoj Federacii na period do 2020 goda / K. N. Kulik [i dr.]. - Volgograd : VNIALMI, 2008. - 34 s.

9. Effects of Governance on Availability of Land for Agriculture and Conservation in Brazil / G. Sparovek [ et al.] // Environmental Science and Technology. - 2015. - Vol. 49, Issue 17. - P. 10285-10293.

10. Forest restoration following surface mining disturbance: shallenges and solitions / S.

E. Masdodals [ et al.] // New Forests. - 2015. - V. 46. , Issis 5 - 6 . P. 703 - 732. 